\title{
Publisher's Note: Characterizing short-term stability for Boolean networks over any distribution of transfer functions [Phys. Rev. E 94, 012301 (2016)]
}

C. Seshadhri, Andrew M. Smith, Yevgeniy Vorobeychik, Jackson R. Mayo, and Robert C. Armstrong (Received 2 September 2016; published 14 September 2016)

DOI: 10.1103/PhysRevE.94.039901

This paper was published online on 5 July 2016 with an error in Ref. [11]. Reference [11] should read as "C. Seshadhri, Y. Vorobeychik, J. R. Mayo, R. C. Armstrong, and J. R. Ruthruff, Influence and Dynamic Behavior in Random Boolean Networks, Phys. Rev. Lett. 107, 108701 (2011)". The reference has been corrected as of 8 September 2016. The reference is incorrect in the printed version of the journal. 